\title{
Interleukin-6 is important for regulation of core body temperature during long-term cold exposure in mice
}

\author{
EMIL EGECIOGLU, FREDRIK ANESTEN, ERIK SCHÉLE and VILBORG PALSDOTTIR \\ Department of Physiology, Institute of Neuroscience and Physiology, \\ The Sahlgrenska Academy, University of Gothenburg, 41390 Gothenburg, Sweden
}

Received March 20, 2018; Accepted June 27, 2018

DOI: $10.3892 /$ br.2018.1118

\begin{abstract}
Interleukin-6 (IL6) is a cytokine important for inducing the fever response during infection and has been reported to uphold core body temperature during acute cold exposure. Recently it has also been indicated that IL6 in serum increases in cold-exposed mice. The aim of the present study was to investigate if IL6 is important for core body temperature regulation following a long-term cold exposure in mice. Experiments were performed with global IL6 deficient (-/-) mice, mice with conditional IL6 receptor $\alpha$ (IL6R $\alpha$ ) knockdown in the central nervous system (CNS; IL6R $\left.\alpha^{\mathrm{NesCr}}\right)$ and appropriate wild-type (Wt) controls. All mice were placed in a cold environment $\left(4^{\circ} \mathrm{C}\right)$ for 6 days. Core body temperature and oxygen consumption were measured by telemetry probes and indirect calorimetry at room temperature $\left(20^{\circ} \mathrm{C}\right)$, and during the first and last day of cold exposure. Brain stem, hypothalamus and white and brown adipose tissues from the cold-exposed mice were subjected to gene expression analysis. After 6 days in $4^{\circ} \mathrm{C}$, the IL6-/- mice exhibited significantly lower body temperature and oxygen consumption compared with Wt mice $(\mathrm{P}<0.05)$. The IL6R $\alpha^{\text {NesCre }}$ mice also exhibited lower body temperature compared with $\mathrm{Wt}^{\mathrm{Nes} C r e}$ controls during the last day of cold exposure $(\mathrm{P}<0.05)$. Furthermore, an increase in the mRNA level of brain-derived neurotrophic factor (Bdnf) was detected in the brain stem of both IL6-/- and IL6R $\alpha^{\text {NesCre }}$ mice compared with the Wt groups $(\mathrm{P}<0.05)$. The finding that body temperature was decreased in IL6-/- and IL6R $\alpha^{\text {NesCre }}$ mice indicates a decrease in thermogenesis in these animals. Bdnf has previously been indicated to increase body temperature and could in the present study be a mechanistic factor involved in counteracting the low body temperature in
\end{abstract}

Correspondence to: Dr Vilborg Palsdottir, Department of Physiology, Institute of Neuroscience and Physiology, The Sahlgrenska Academy, University of Gothenburg, 11 Medicinaregatan, 41390 Gothenburg, Sweden

E-mail: vilborg.palsdottir@neuro.gu.se

Key words: interleukin-6, thermogenesis, cold exposure, body temperature, energy expenditure, brown adipose tissue, hypothalamus, brain stem
IL6-/- and IL6R $\alpha^{\text {NesCre }}$ mice. These results suggest that IL6 is not only involved in body temperature regulation during infection, but also during long-term cold exposure, probably through mechanisms in the CNS.

\section{Introduction}

Thermoregulation is an important tool that enables mammals to adapt to changes in ambient temperature and also serves a role in defence against infections. In mammals, there are mechanisms involving the cytokines interleukin (IL)1 $\beta$, IL6 and tumour necrosis factor- $\alpha$ that have been reported to increase body temperature in infection and initialize the fever response (1-4). In a cold climate the body also needs thermogenesis to maintain body temperature, and in this regard, it is mainly central sympathetic signalling that induces production of heat (5). In previous studies, it has been indicated that IL4 and IL13 activate macrophages to secrete catecholamines, which enhance and sustain the thermogenic response $(6,7)$. In mice, a substantial portion of this heat is produced in the brown adipose tissue (BAT) (8).

Since IL6 is among the factors considered to induce thermogenesis in infection, the present study aimed to investigate whether IL6 is also important for cold induced thermogenesis. There is data to suggest that IL6 serum levels are increased during cold exposure in mice (9). Furthermore, IL6 deficient (-/-) mice exposed to $4^{\circ} \mathrm{C}$ during a relatively short $(8 \mathrm{~h})$ period exhibited $2.5^{\circ} \mathrm{C}$ lower core body temperature compared with wild-type (Wt) mice exposed to the same condition (10). Given that the initial phase of cold-induced thermogenesis originates mainly from shivering and other adaptations to cold rather than non-shivering thermogenesis (11), the present study wanted to investigate if IL6 is involved in adaptation to long-term exposure to cold, i.e. non-shivering thermogenesis.

It has been reported that IL6-/- mice exposed to $4^{\circ} \mathrm{C}$ for 3 days exhibited a lower content of uncoupling protein 1 (Ucp1) protein in inguinal white adipose tissue (WAT) compared with Wt mice housed under the same conditions (12), which further implies that the thermoregulation of IL6-/- mice may also differ from Wt mice when exposed to cold over a longer time period. The present aim was to investigate the hypothesis that IL6 is important for maintaining body temperature during 6 days of cold exposure. 
A brain-specific IL-6 knockout mouse model was also used to determine if IL6 signalling in the central nervous system (CNS) is important for the thermogenesis response. The main findings in the present study supported the hypothesis that IL6 and IL6R $\alpha$ are important for body temperature regulation in cold-exposed mice.

\section{Materials and methods}

Animals. Global IL6 deficient (IL6-/-) mice on a C57BL/6 background and C57BL/6 Wt control mice were obtained from Jackson Laboratories (Bar Harbor, ME, USA). For conditional inactivation of IL6 receptor $\alpha$ (IL6R $\alpha$ ) in the CNS, transgenic mice expressing the Cre recombinase under the control of the Nestin promoter and enhancer (Jackson Laboratories) (13) and with intact IL6R $\alpha$ gene (IL6R $\alpha^{+/+}$) were bred to homozygous IL6R $\alpha^{\text {loxP/loxP }}$ mice in the animal facility at the University of Gothenburg (Gothenburg, Sweden). The resulting heterozygous F1 offspring (IL6R $\alpha^{+/ l o x P}$ ) were either positive or negative for Nestin-Cre. From mating of IL6R $\alpha^{+/ l o x P}$ with IL $6 \mathrm{R} \alpha^{+/ l o x P}$ Nestin-Cre mice, $\mathrm{F}_{2}$ animals were obtained of the desired genotypes [IL6R $\alpha^{\text {loxP/loxP }}$ Nestin-Cre (IL6R $\alpha^{\mathrm{NesCr}}$ ) and IL6R $\alpha^{+/+}$ Nestin-Cre $\left.\left(\mathrm{Wt}^{\mathrm{Nes} C r e}\right)\right]$. $\mathrm{Wt}^{\mathrm{Nes} C r e}$ mice were used as control littermates for conditional IL6R $\alpha$ knockout mice. All animal procedures were approved by the Committee on the Ethics of Animal Experiments at the University of Gothenburg, Sweden (permit no. 142-2014), and were conducted in accordance with the EU Directive 2010/63/EU for animal experiments (14).

The study was performed in two separate cohorts of animals (IL6-/- or IL6R $\alpha^{\text {NesCre }}$ mice and their corresponding Wt controls, respectively.) The first cohort comprised 3-month-old male IL6-/- $(\mathrm{n}=10)$ and $\mathrm{Wt}(\mathrm{n}=10)$ mice weighing $27.6 \pm 0.7 \mathrm{~g}$ and $27.7 \pm 0.4 \mathrm{~g}$, respectively, and the second cohort comprised 7-month-old male IL6R $\alpha^{\text {NesCre }}(n=6)$ and $\mathrm{Wt}^{\mathrm{NesCre}}$ $(\mathrm{n}=10)$ mice weighing $33.2 \pm 1.3 \mathrm{~g}$ and $35.2 \pm 0.6 \mathrm{~g}$, respectively. All male mice with the correct genotype were included, despite there being unequal group sizes. All mice were housed 4-5 per cage under standard conditions at $20-22^{\circ} \mathrm{C}$ and $\sim 50 \%$ humidity, with free access to food (Teklad global $16 \%$ protein rodent diet; Envigo, Huntingdon, UK) and water, and under a 12-h light/dark cycle (lights on from 7 a.m. to 7 p.m.).

Body temperature, oxygen consumption and locomotor activity. Telemetry devices (G2 E-mitter, MiniMitter, Bend, OR, USA) were implanted via a $1 \mathrm{~cm}$ incision through the skin and peritoneum. Following implantation the peritoneum was sewed with Polysorb 5-0 suture (Covidien, Dublin, Ireland) and the skin was closed with Reflex 7 clips (CellPoint Scientific, Inc., Gaithersburg, MD, USA). The surgery was performed under 3\% isoflurane (Baxter, Deerfield, IL, USA) anaesthesia. The mice were left to recover for 1 week prior to the start of experiments. After recovery from telemetry implantation the mice were housed individually and gradually brought from $20^{\circ} \mathrm{C}$ to $4^{\circ} \mathrm{C}$ over a period of $6 \mathrm{~h}$ and kept at $4^{\circ} \mathrm{C}$ for 6 days. Animals had free access to fresh water and standard food pellets (Tekland Global $16 \%$ protein rodent diet), and were kept under standardized conditions as above. Body weight and food intake was recorded every day during the cold exposure experiment and the mice were euthanized by intraperitoneal injection of a mixture of $150 \mathrm{mg} / \mathrm{kg}$ ketamine
(Ketaminol; Intervet, Boxmeer, the Netherlands) and $2 \mathrm{mg} / \mathrm{kg}$ medetomidine (Domitor vet., Orion Pharma, Espoo, Finland) and confirmed by decapitation immediately following the cold exposure period.

Oxygen consumption and carbon dioxide production were measured by indirect calorimetry in an INCA metabolic system (Somedic, Hörby, Sweden) as previously described (10). The system comprises a sealed chamber with regulated air flow and temperature. It also includes sensors for the MiniMitter telemetry system, which are designed to measure core body temperature with $0.01^{\circ} \mathrm{C}$ accuracy and three-dimensional locomotor activities via the implanted G2 E-mitter transponders. The data were collected every minute for all variables except oxygen consumption, which was measured every second minute, over $24 \mathrm{~h}$. The individual baseline oxygen consumption and core body temperature was established at $20^{\circ} \mathrm{C}$ and calculated as mean values of all time-points when the animal was at rest (no locomotor activity). The same strategy was used to calculate oxygen consumption and core body temperature during the first and sixth day of exposure to $4^{\circ} \mathrm{C}$.

Gene expression analysis. The hypothalamus, brain stem, interscapular BAT and retroperitoneal WAT were dissected, snap frozen in liquid nitrogen and kept at $-80^{\circ} \mathrm{C}$ until analysis. The tissues were homogenized in Qiazol (Qiagen $\mathrm{GmbH}$, Hilden, Germany) and mRNA was extracted using an RNeasy Lipid Tissue Mini kit, according to the manufacturer's instructions (Qiagen). The mRNA concentration of the samples was measured by NanoDrop spectrophotometry (NanoDrop Technologies; Thermo Fisher Scientific, Inc., Wilmington, DE, USA). cDNA was synthesized from $1 \mu \mathrm{g}$ mRNA with an iScript cDNA synthesis kit (Bio-Rad Laboratories, Inc., Hercules, CA, USA).

Real time quantitative PCR (qPCR) for BAT and WAT samples was performed in duplicate using Step-One-Plus (Applied Biosystems; Thermo Fisher Scientific, Inc., Waltham, MA, USA) under the following conditions: initial denaturation, $10 \mathrm{~min} / 95^{\circ} \mathrm{C} ; 40$ cycles, $15 \mathrm{sec} / 95^{\circ} \mathrm{C}, 60 \mathrm{sec} / 60^{\circ} \mathrm{C}$. The brain stem and hypothalamus samples were analysed by qPCR using an ABI Prism 7900 Sequence Detection system (Applied Biosystems) under the conditions: initial denaturation, $20 \mathrm{sec} / 95^{\circ} \mathrm{C} ; 40$ cycles, $1 \mathrm{sec} / 95^{\circ} \mathrm{C}, 20 \mathrm{sec} / 60^{\circ} \mathrm{C}$. The brain stem and hypothalamus samples were analysed in duplicate with Universal Taqman MasterMix containing AmpliTaq Gold $^{\circledR}$ DNA polymerase (Applied Biosystems; Thermo Fisher Scientific Inc.) and primer-probe assays for agouti related protein (Agrp; Mm00475829_g1), brain-derived neurotrophic factor (Bdnf; Mm04230607_s1), ciliary neurotrophic factor (Cntf; Mm00446373_m1), preproglucagon (Gcg; Mm01269055_m1), neuropeptide Y (Npy; Mm00445771_m1), tyrosine hydroxylase (Th; Mm00447557_m1) and Ucp2 (Mm00627599_m1) and were normalized to glucuronidase $\beta$ (Mm00446953_m1). The BAT and WAT samples were analysed with Taqman Fast Advanced Master Mix containing AmpliTaq ${ }^{\circledR}$ Fast DNA Polymerase (Applied Biosystems) and primer-probe assays for Ucp1 (Mm01244861_m1), fibroblast growth factor 21 (Fgf21; Mm00840165_g1), peroxisome proliferative activated receptor $\gamma$, coactivator $1-\alpha$ (Pgc1a; Mm01208835_m1), as well as for Npy and Th, and were normalized to TATA box binding protein (Mm00446971_m1). All primer-probe assays 

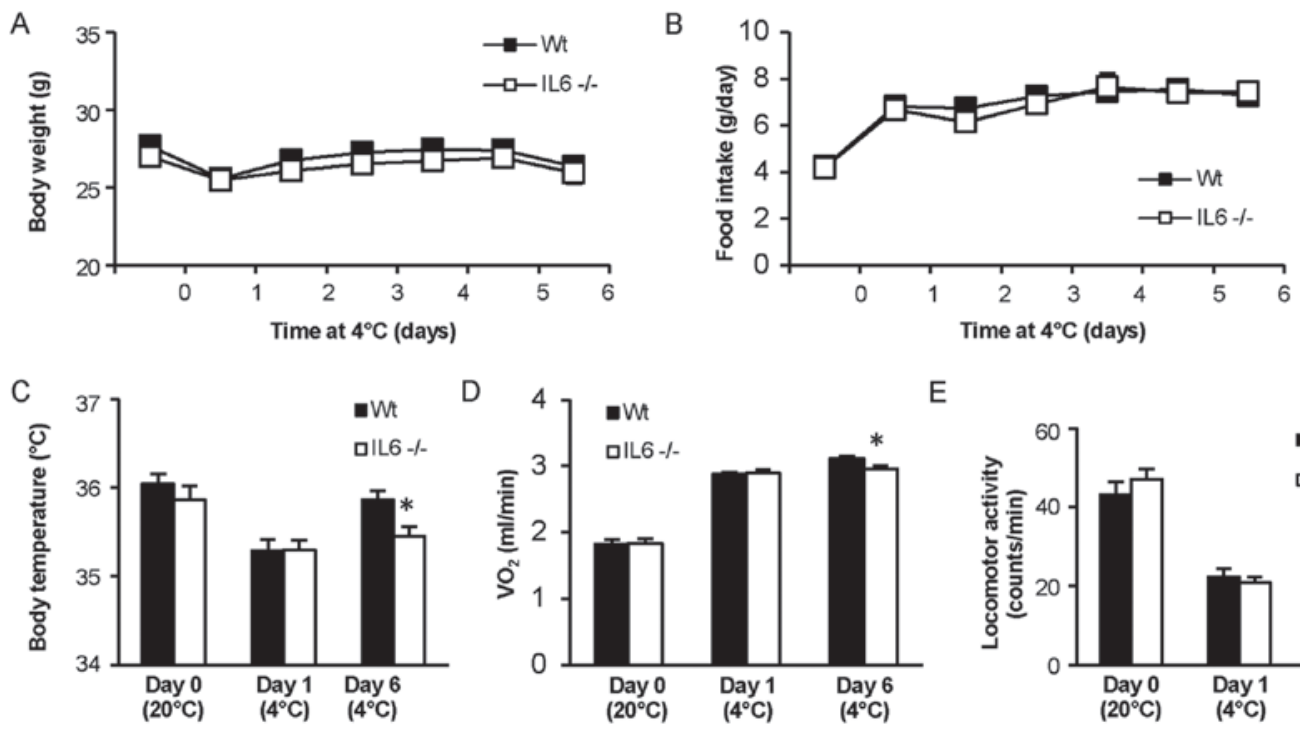

E

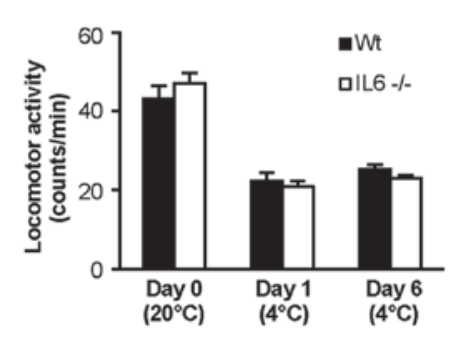

Figure 1. Physiological parameters during cold exposure in IL6-/- mice. (A) Body weight, (B) food intake, (C) body temperature, (D) oxygen consumption $\left(\mathrm{VO}_{2}\right)$ and $(\mathrm{E})$ locomotor activity in $\mathrm{Wt}(\mathrm{n}=10)$ and IL6-deficient $(\mathrm{IL6}-/-; \mathrm{n}=10)$ mice at baseline $\left(20^{\circ} \mathrm{C}\right)$ and during cold exposure $\left(4^{\circ} \mathrm{C}\right)$. Data are presented as mean \pm standard error of the mean. ${ }^{*} \mathrm{P}<0.05$. IL6, interleukin-6; Wt, wild-type.

included a TaqMan probe with a fluorescent dye label (FAM) and were purchased from Applied Biosystems (Thermo Fisher Scientific, Inc.). The relative mRNA levels were obtained by using the comparative threshold cycle $(\mathrm{Cq})$ method, and calculated with the $\Delta \Delta \mathrm{Cq}$ equation (15).

Statistics. Statistical analyses were performed using IBM SPSS Statistics v20 (IBM Corp., Armonk, NY, USA). Data were analysed using Student's t-test, with $\mathrm{P}<0.05$ considered to indicate statistical significance. All data were presented as the mean \pm standard error of the mean, and the mRNA expression levels in the Wt mouse groups were set to $100 \%$ for relative comparison.

\section{Results}

Body weight, food intake, body temperature, oxygen consumption and locomotor activity in global IL6-/- mice. Body weight did not significantly differ between the IL6-/- and Wt mice at any time-point during the experiment (Fig. 1A). Food intake was also similar between the groups and increased markedly in both groups when exposed to lower ambient temperature (Fig. 1B). Core body temperature did not differ between IL6-/- and Wt mice at room temperature $\left(20^{\circ} \mathrm{C}\right)$ or during the first day of cold exposure (Fig. 1C), and neither did oxygen consumption during baseline conditions or the first day at $4^{\circ} \mathrm{C}$ (Fig. 1D). However, after 6 days in $4^{\circ} \mathrm{C}$ the IL6-/mice exhibited significantly lower body temperature $(\mathrm{P}<0.05)$ and oxygen consumption $(\mathrm{P}<0.05)$ compared with $\mathrm{Wt}$ mice. Locomotor activity did not significantly differ between the groups throughout the measurement period (Fig 1E).

Body weight, food intake, body temperature, oxygen consumption and locomotor activity in mice with conditional IL6Ra knockdown in the CNS. Body weight did not significantly differ between IL6R $\alpha^{\mathrm{NesCre}}$ and $\mathrm{Wt}^{\mathrm{Nes} C \mathrm{Cr}}$ mice at baseline or during the cold exposure (Fig. 2A). Food intake did not differ between the groups during the experiment, and an increase in food intake of similar magnitude was observed for both IL6R $\alpha^{\text {NesCre }}$ and $\mathrm{Wt}^{\mathrm{NesCre}}$ mice when the temperature was reduced to $4^{\circ} \mathrm{C}$ (Fig. 2B). Core body temperature did not differ between IL6R $\alpha^{\mathrm{NeSCre}}$ and $\mathrm{Wt}^{\mathrm{NesCre}}$ mice at room temperature or during the first day of cold exposure, but similarly to global IL6-/mice, core body temperature was lower in the IL6R $\alpha^{\mathrm{Nes} C r e}$ mice compared with controls after 6 days at $4^{\circ} \mathrm{C}(\mathrm{P}<0.05$; Fig $2 \mathrm{C})$. However, the IL6 knockdown in the CNS did not affect oxygen consumption (Fig. 2D) or locomotor activity (Fig. 2E).

Gene expression in the brain stem and hypothalamus. The mRNA expression of Bdnf, Gcg and Th was increased 40-50\% in the brain stem of IL6-/- mice compared with in Wt mice after 6 days at $4^{\circ} \mathrm{C}(\mathrm{P}<0.05$; Fig. 3A). The mRNA expression of Bdnf was also higher in the brain stem of IL6R $\alpha^{\mathrm{Nes} C r e}$ mice compared with in $\mathrm{Wt}^{\mathrm{Nes} C r e}$ mice exposed to $4^{\circ} \mathrm{C}(\mathrm{P}<0.05)$, but the mRNA levels of Gcg and Th did not differ between these mice (Fig. 3B). In contrast to the brainstem, no difference was detected in the mRNA expression of Bdnf or Th in the hypothalamus of IL6-/- mice or IL6R $\alpha^{\text {NesCre }}$ mice (Fig. 3C and D). In the hypothalamus from the IL6-/- mice there was a tendency for increased mRNA expression of Npy compared with Wt levels ( $\mathrm{P}=0.053$; Fig. 3C). Increased hypothalamic expression of Cntf mRNA $(\mathrm{P}<0.05)$ and decreased hypothalamic expression of Ucp2 mRNA $(\mathrm{P}<0.05)$ were identified in IL6R $\alpha^{\text {NesCre }}$ mice compared with $\mathrm{Wt}^{\mathrm{Nes} C r e}$ levels (Fig. 3D).

Gene expression in BAT and WAT. There were no significant differences in the mRNA levels of Ucp1, Pgcla, Fgf21, Npy and Th in BAT between IL6-/- and Wt mice after 6 days at $4^{\circ} \mathrm{C}$ (Fig. 4A), nor in the same genes in BAT from IL6 R $\alpha^{\text {NesCre }}$ mice compared with $\mathrm{Wt}^{\mathrm{Nes} C r e}$ mice under the same conditions (Fig. 4B). Similarly, no differences were identified in the gene expressions of Ucp1, Pgc1a, Fgf21, Npy and Th in the WAT of IL6-/- mice (Fig. 4C). In the WAT of the IL6Ra ${ }^{\mathrm{Nes} C r e}$ mice, a tendency for lower Pgcla mRNA levels $(\mathrm{P}=0.053)$ and 


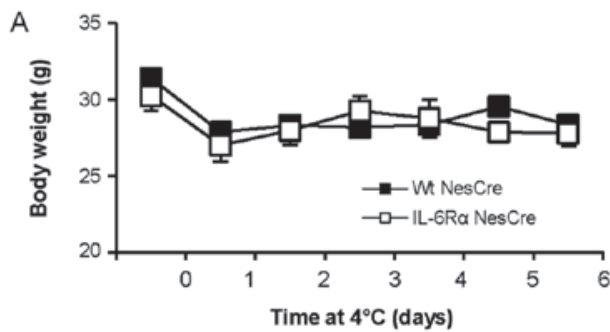

B
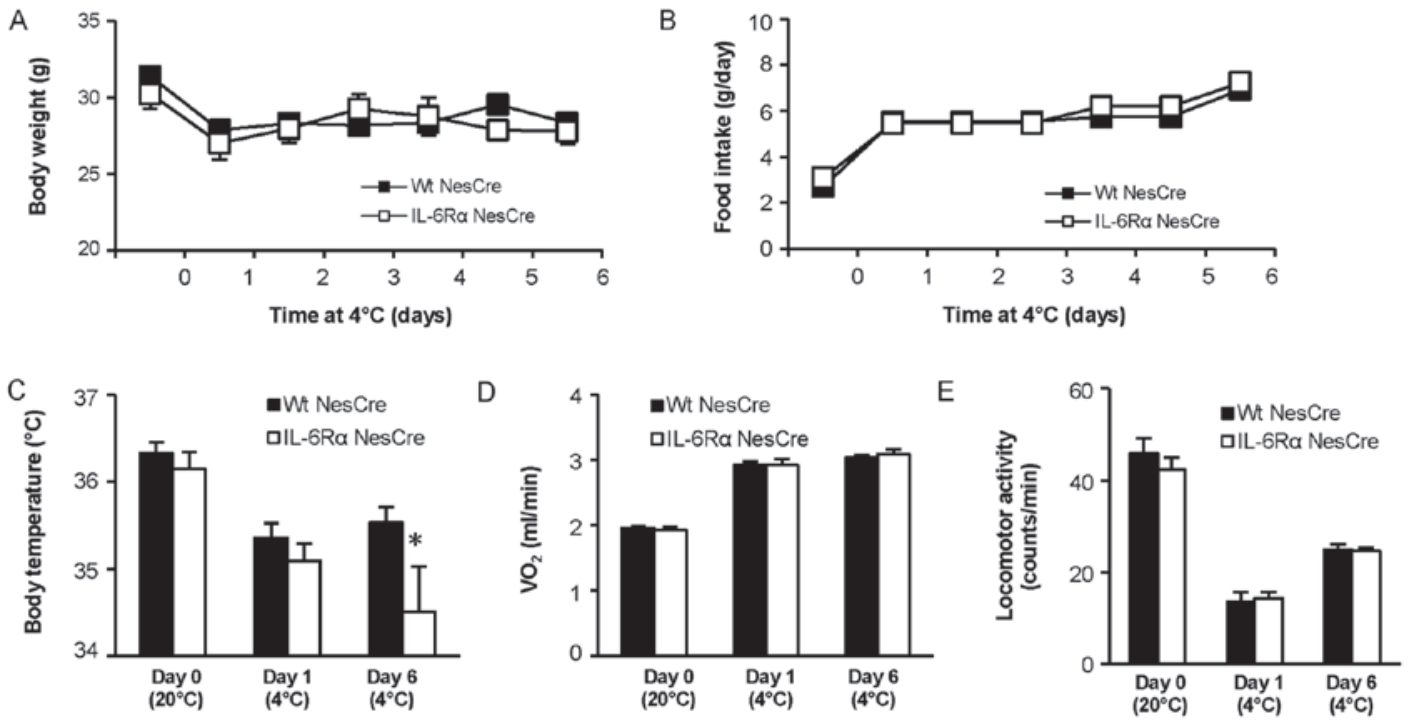

Figure 2. Physiological parameters during cold exposure in IL6R $\alpha^{\text {NesCre }}$ mice. (A) Body weight, (B) food intake, (C) body temperature, (D) oxygen consumption $\left(\mathrm{VO}_{2}\right)$ and $(\mathrm{E})$ locomotor activity in IL6R $\alpha^{+++}$Nestin-Cre $\left(\mathrm{Wt}^{\mathrm{Nes} C r e} ; \mathrm{n}=10\right)$ and IL6R $\alpha^{\text {loxPloxP }}$ Nestin-Cre (IL6R $\left.\alpha^{\text {NesCree }} ; \mathrm{n}=6\right)$ mice at baseline $\left(20^{\circ} \mathrm{C}\right)$ and during cold exposure $\left(4^{\circ} \mathrm{C}\right)$. Data are presented as mean \pm standard error of the mean. ${ }^{*} \mathrm{P}<0.05$. IL6R $\alpha$, interleukin- 6 receptor $\alpha$; Wt, wild-type.

A
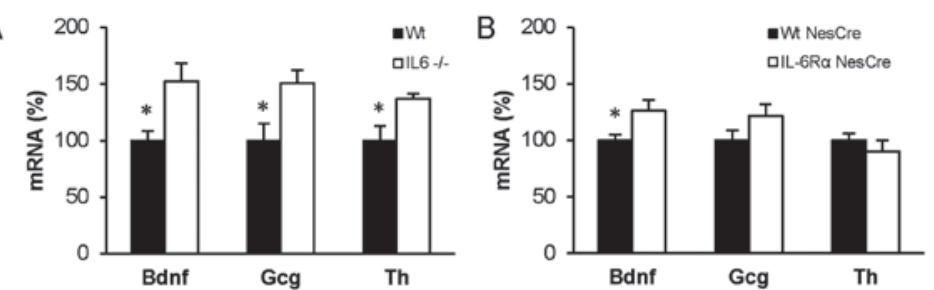

C
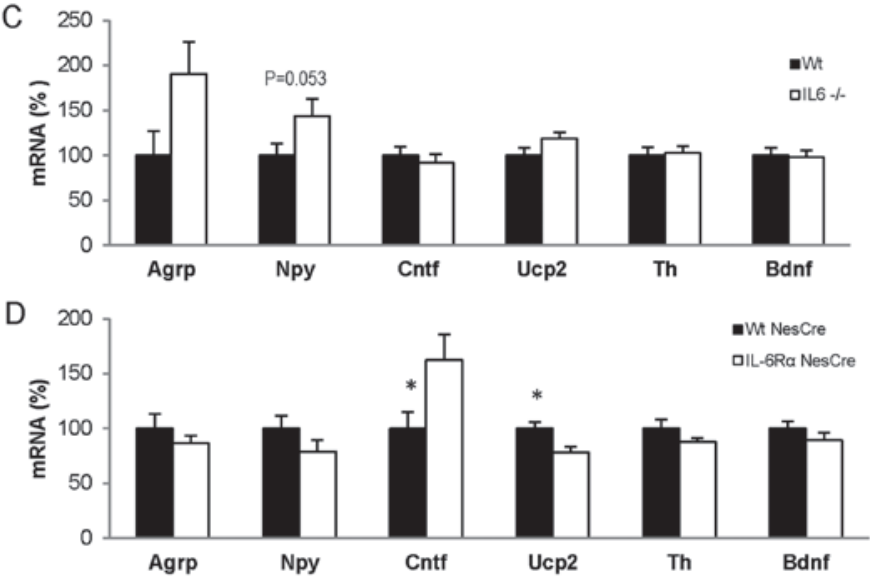

Figure 3. mRNA expression in brain from mice exposed to $4^{\circ} \mathrm{C}$ for 6 days. mRNA expression in (A and B) brain stem and (C and D) hypothalamus from Wt

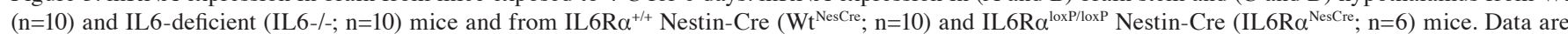
presented as mean \pm standard error of the mean. "P $<0.05$. IL6, interleukin-6; IL6R $\alpha$, interleukin-6 receptor $\alpha$; Wt, wild-type; Bdnf, brain-derived neurotrophic factor; Gcg, preproglucagon; Th, tyrosine hydroxylase; Agrp, agouti related protein; Npy, neuropeptide Y; Cntf, ciliary neurotrophic factor; Ucp2, uncoupling protein 2.

a significant decrease in Npy levels $(\mathrm{P}<0.05)$ compared with control levels were identified (Fig. 4D).

\section{Discussion}

Body temperature was decreased in IL6-/- as well as IL6R $\alpha^{\text {NesCre }}$ mice compared with respective Wt controls after 6 days of cold exposure, indicating a decrease in thermogenesis. Additionally, oxygen consumption in IL6-/- mice was lower compared with Wt mice after 6 days at $4^{\circ} \mathrm{C}$, indicating lower energy expenditure in these mice. As mice with conditional IL6R $\alpha$ knockdown in the CNS did exhibit lower body temperature after 6 days of cold exposure, this suggests that the IL6 signalling in the brain may be of importance for thermogenesis during cold exposure.

Thermogenesis during cold exposure is an important homeostatic mechanism in mammals involving several tissues including the brain, BAT and skeletal muscle $(5,16)$. A previous 

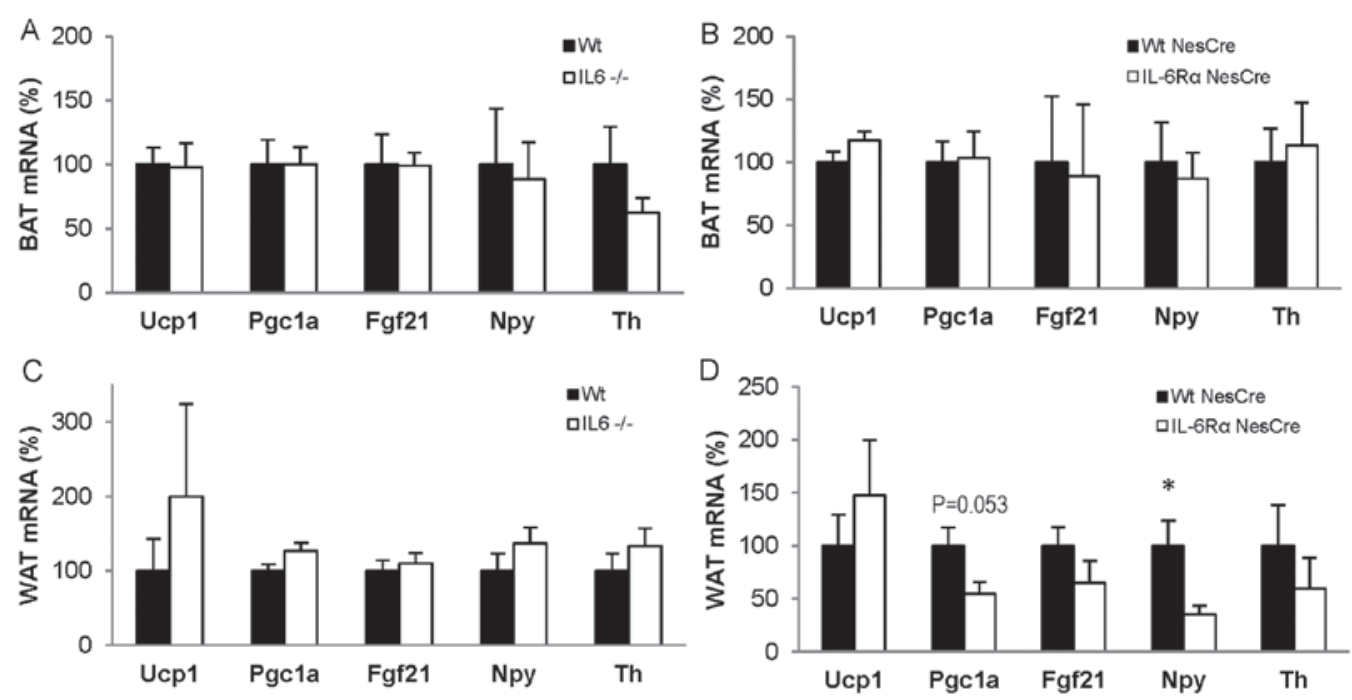

Figure 4. mRNA expression in adipose tissue from mice exposed to $4^{\circ} \mathrm{C}$ for 6 days. mRNA expression in (A and B) BAT and (C and D) WAT from Wt ( $\left.=10\right)$ and IL6-deficient (IL6-/-; n=10) mice and from IL6R $\alpha^{+/+}$Nestin-Cre $\left(\mathrm{Wt}^{\mathrm{Nes} C r e} ; \mathrm{n}=10\right)$ and IL6R $\alpha^{\text {loxP/loxP }}$ Nestin-Cre $\left(\right.$ IL6R $\alpha^{\text {NesCre. }}$ n=6) mice. Data are presented as mean \pm standard error of the mean. * P<0.05. IL6, interleukin-6; IL6R $\alpha$, interleukin-6 receptor $\alpha$; Wt, wild-type; BAT, brown adipose tissue; WAT, white adipose tissue; Ucp1, uncoupling protein 1; Pgc1a, peroxisome proliferative activated receptor $\gamma$, coactivator 1- $\alpha$; Fgf21, fibroblast growth factor 21; Npy, neuropeptide $\mathrm{Y}$; Th, tyrosine hydroxylase.

view of the different roles of tissues involved in thermogenesis was that the skeletal muscle was mainly involved in shivering thermogenesis while BAT was the main tissue responsible for non-shivering thermogenesis (17). More recently there has been data to suggest that skeletal muscle is also important for non-shivering thermogenesis in mammals $(16,18,19)$. However, the present study focused on the BAT, WAT and the brain, but not the skeletal muscle component of thermogenesis. In future studies it would be interesting to investigate the expression of mitochondria-associated genes in skeletal muscle following cold exposure in IL6-/- mice, since IL6 is expressed in skeletal muscle following muscle contractions (20).

In a recent study, the IL6 levels in serum were demonstrated to increase in mice following 15 days of exposure to cold temperature $\left(4^{\circ} \mathrm{C}\right)(9)$. Furthermore, decreased body temperature observed in the present study in IL6-/- mice housed for 6 days in cold ambient temperature indicates that the decrease in temperature in cold-exposed IL6-/- for $8 \mathrm{~h}$ (10) is not transient. Thus, the present results suggest that the previously observed acute decrease in body temperature in IL6-/- mice may be due to an incomplete thermogenesis response to the cold environment and not just a stress effect of sudden decrease in ambient temperature.

The adaption to lower ambient temperature was evident by the increases in food intake and oxygen consumption in all mice independent of genotype. Both Wt and IL6-/- mice ate close to double the quantity of food per day in cold temperature $\left(4^{\circ} \mathrm{C}\right)$ compared with when housed at room temperature $\left(20^{\circ} \mathrm{C}\right)$, and since there was no difference in food intake between mice with different genotypes, food intake as a cause of differing body temperature seems unlikely. However, the IL6-/- mice consumed significantly less oxygen after 6 days at cold ambient temperature compared with the Wt mice, suggesting that lower energy expenditure may in part explain the lower body temperature in IL6-/- mice. The lower energy expenditure in combination with increased food intake in the IL6-/- mice may in the long-term result in increased fat mass, in line with previously published results of mature-onset obesity in IL6-/- mice (21).

The IL6R $\alpha^{\text {NesCre }}$ mice also exhibited a lower body temperature after 6 days of cold exposure compared with the control mice, but no marked differences in food intake or oxygen consumption. This may indicate that the mice with brain-specific loss of IL6R $\alpha$ are attempting to compensate for the lower body temperature in a distinct way to the global IL6-/- mice. For instance, there is a possibility that these mice have decreased recruitment of BAT thermogenesis, which could initiate hyper-recruitment of non-shivering thermogenesis in muscle, as previously reported in Ucp1-/- mice (22) and mice with ablated BAT (19).

The mRNA expressions of Bdnf, Gcg and Th were increased in the brain stem of IL6-/- mice after 6 days of cold exposure. Hindbrain injections of Bdnf have previously been identified to increase core body temperature in rats, indicating that the brain stem is important for mediating the thermogenesis response (23). Furthermore, Bdnf in the hypothalamus, particularly in the medial and posterior paraventricular regions, may stimulate adaptive thermogenesis in BAT (24). The present study observed no difference in Bdnf mRNA levels in the hypothalamus (without dissecting separate nuclei), but the finding of increased Bdnf in the brain stem of cold-exposed IL6-/- mice indicates that Bdnf in the brain stem may be among the mechanistic factors involved in counteracting the low body temperature in IL6-/- and IL6R $\alpha^{\mathrm{Nes} C r e}$ mice.

Gcg is a complex gene that via different splicing variants encodes glucagon, glucagon like peptide (Glp)1 and Glp2. In the brain stem the Gcg product is spliced into Glp1 and Glp2, which are produced in equal quantities (25), and therefore the increase in Gcg detected in the brain stem probably mirrors an increase in Glp1, which has previously been reported to increase BAT thermogenesis (26-28). Th is required in the synthesis of noradrenalin, and noradrenalin is required to 
activate BAT thermogenesis (8). Since IL6-/- mice exhibited a lower body temperature than Wt mice, the increase of Gcg and Th may be a mechanism attempting to increase thermogenesis in BAT through the Glp1 and catecholamine pathways.

mRNA expression profiles in the hypothalamus exhibited an increase in the neurotrophic factor Cntf in the IL6R $\alpha^{\text {NesCre }}$ mice compared with controls. Cntf is a member of the IL6 family with effects on energy balance (29), and the loss of IL6R $\alpha$ signalling specifically in the brain of the IL6R $\alpha^{\mathrm{NesC} C \mathrm{C}}$ mice may have possibly induced a compensatory increase in Cntf expression in the hypothalamus of these mice. Overexpression of Ucp2 in specific neurons in the hypothalamus has been reported to decrease core body temperature in mice (30), and UCP2 may also co-localize with Agrp/Npy in the hypothalamus and influence their metabolic regulation (31). The decreased levels of Ucp2 in the hypothalamus of IL6R $\alpha^{\mathrm{Nes} C r e}$ mice may have been a method for increasing the body temperature of these mice. In a previous study by our group an increase in the mRNAs of the orexigenic genes Agrp and Npy was noted in the hypothalamus of IL6-/mice compared with Wt mice after 4 weeks at cold ambient temperature (32). This was not as evident after 6 days of cold exposure, but was close to reaching significance for Npy in this present study. NPY signalling from the arcuate nucleus of the hypothalamus has been identified to decrease Th mRNA in the brain stem and hypothalamus, resulting in decreased BAT thermogenesis (33). However, decrease in Th mRNA in the hypothalamus was not identified presently, and conversely, an increase of Th mRNA was observed in the brain stem of the IL6-/- mice. The reason for the tendency towards increased expression of Npy and Agrp is unclear, given that no significant difference was determined in food intake at $4^{\circ} \mathrm{C}$ between the mouse groups.

Implications of the present study may be limited, as in the hypothalamus of IL6R $\alpha^{\text {NesCre }}$ mice, an increase in Agrp, Npy or Th mRNA compared with control levels was not detected. In future studies it would be interesting to expose these mice to a longer cold exposure, to investigate if the cold ambient condition would eventually induce upregulation of Npy, Agrp and Th as seen in the IL6-/- mice.

Npy and Th in BAT have also been suggested to contribute to BAT-based thermogenesis during cold exposure (34). In the present study, the mRNA levels of Npy and Th in BAT were similar between groups, but a significant decrease of Npy mRNA was identified in the WAT of IL6R $\alpha^{\text {NesCre }}$ mice compared with controls. This may indicate a role of NPY in the browning of WAT, a process defined as increased Ucp1 expression in WAT (35), besides the recruitment of BAT thermogenesis.

Ucp1 mRNA expression in WAT did not differ between IL6-/- and Wt mice after 6 days of cold exposure, which is in line with the previous finding of no difference between IL6-/and Wt mice after 3 days of exposure to $4^{\circ} \mathrm{C}$ (12). However, Knudsen et al (12) observed a lower Ucp1 protein content in inguinal WAT of IL6-/- mice compared with Wt mice, indicating that IL6 could have an impact on Ucp1 protein content, although the mRNA levels do not differ. The gene expression of the thermogenic biomarkers Pgc1a, and Fgf21 was not decreased in the IL6-/- mice, but there was a near significant decrease of Pgcla in the WAT of IL6R $\alpha^{\mathrm{Nes} C r e}$ mice, indicating a lower degree of browning of WAT in these mice (36). However, the present study did not perform histology of WAT or BAT, which may have been informative regarding, for instance, the degree of browning of the WAT. With regard to Ucp1 in BAT, the mRNA levels were similar to controls in both global IL6-/- and brain specific IL6R $\alpha^{\mathrm{NesCre}}$ mice after 6 days of cold exposure. Previous studies of IL6-/- mice at room temperature and after 3 days of cold exposure identified no difference in Ucp1 protein content between IL6-/- and controls $(10,12)$. The possible role of IL6 in increasing the thermogenesis activity in BAT is therefore not obvious. However, there is one study indicating an association between chronic elevation of IL6 in the CNS and increased Ucp1 protein levels in BAT in rats (37). This elevation in Ucp1 levels was not observed in denervated BAT tissue, indicating that sympathetic nerve signalling may be involved (37).

Collectively, the data suggest that IL6 is not only involved in body temperature regulation during infection, but also contributes to long-term cold induced thermogenesis. Furthermore, the results from brain-specific knockdown of IL6R $\alpha$ indicate that the impact of IL6 on thermogenesis is mediated by IL6R $\alpha$ signalling in the brain.

\section{Acknowledgements}

Michael Axelsson and Ola Svensson are gratefully acknowledged for providing access to the climate chamber at the Zoology Department, University of Gothenburg, Sweden. The abstract was presented at the European Obesity Summit (EOS) - Joint Congress of EASO and IFSO-EC 1-4 June 2016 in Gothenburg, Sweden, and published as abstract no. PO1.046 in Obes Facts 9 (Suppl 1): 2016.

\section{Funding}

No funding was received.

\section{Availability of data and materials}

All data generated or analyzed during this study are included in this published article.

\section{Authors' contributions}

EE designed the study, performed the implantation of telemetry devices and dissected tissues. FA performed the in vivo experiments and dissected tissues. ES performed the gene expression analysis of the tissues and interpreted the corresponding data. VP designed the study, performed the in vivo experiments, analysed and interpreted the physiological data, performed the gene expression analysis and wrote the manuscript. All authors read and approved the final study.

\section{Ethics approval and consent to participate}

All animal procedures were approved by the Committee on the Ethics of Animal Experiments at the University of Gothenburg, Sweden (permit no. 142-2014) and were conducted in accordance with the EU Directive 2010/63/EU for animal experiments. 


\section{Patient consent for publication}

Not applicable.

\section{Competing interests}

The authors declare that they have no competing interests.

\section{References}

1. Luheshi GN: Cytokines and fever. Mechanisms and sites of action. Ann N Y Acad Sci 856: 83-89, 1998.

2. Leon LR: Invited review: cytokine regulation of fever: studies using gene knockout mice. J Appl Physiol 1985 92: 2648-2655, 2002.

3. Sundgren-Andersson AK, Ostlund P and Bartfai T: IL-6 is essential in TNF-alpha-induced fever. Am J Physiol 275: R2028-R2034, 1998.

4. Zetterström M, Sundgren-Andersson AK, Ostlund P and Bartfai T: Delineation of the proinflammatory cytokine cascade in fever induction. Ann N Y Acad Sci 856: 48-52, 1998.

5. Morrison SF and Nakamura K: Central neural pathways for thermoregulation. Front Biosci 16: 74-104, 2011.

6. Nguyen KD, Qiu Y, Cui X, Goh YP, Mwangi J, David T, Mukundan L, Brombacher F, Locksley RM and Chawla A: Alternatively activated macrophages produce catecholamines to sustain adaptive thermogenesis. Nature 480: 104-108, 2011.

7. Qiu Y, Nguyen KD, Odegaard JI, Cui X, Tian X, Locksley RM, Palmiter RD and Chawla A: Eosinophils and type 2 cytokine signaling in macrophages orchestrate development of functional beige fat. Cell 157: 1292-1308, 2014.

8. Cannon B and Nedergaard J: Brown adipose tissue: Function and physiological significance. Physiol Rev 84: 277-359, 2004.

9. Bal NC, Maurya SK, Pani S, Sethy C, Banerjee A, Das S, Patnaik S and Kundu CN: Mild cold induced thermogenesis: Are BAT and skeletal muscle synergistic partners? Biosci Rep 37: BSR20171087, 2017.

10. Wernstedt I, Edgley A, Berndtsson A, Fäldt J, Bergström G Wallenius V and Jansson JO: Reduced stress- and cold-induced increase in energy expenditure in interleukin-6-deficient mice. Am J Physiol Regul Integr Comp Physiol 291: R551-R557, 2006.

11. Cannon B and Nedergaard J: Nonshivering thermogenesis and its adequate measurement in metabolic studies. J Exp Biol 214 242-253, 2011

12. Knudsen JG, Murholm M, Carey AL, Biensø RS, Basse AL, Allen TL, Hidalgo J, Kingwell BA, Febbraio MA, Hansen JB, et al: Role of IL-6 in exercise training- and cold-induced UCP1 expression in subcutaneous white adipose tissue. PLoS One 9: e84910, 2014.

13. Reichardt HM, Kellendonk C, Tronche F and Schütz G: The Cre/lox P system--a versatile tool to study glucocorticoid signalling in mice. Biochem Soc Trans 27: 78-83, 1999.

14. Directive 2010/63/EU of the European Parliament and of the Council of 22 September 2010 on the protection of animals used for scientific purposes. OJ L 276: 33-79. 2010.

15. Livak KJ and Schmittgen TD: Analysis of relative gene expression data using real-time quantitative PCR and the 2(-Delta Delta C(T)) Method. Methods 25: 402-408, 2001.

16. Rowland LA, Bal NC and Periasamy M: The role of skeletal-muscle-based thermogenic mechanisms in vertebrate endothermy. Biol Rev Camb Philos Soc 90: 1279-1297, 2015.

17. Morrison SF, Nakamura K and Madden CJ: Central control of thermogenesis in mammals. Exp Physiol 93: 773-797, 2008.

18. Pant M, Bal NC and Periasamy M: Sarcolipin: A key thermogenic and metabolic regulator in skeletal muscle. Trends Endocrinol Metab 27: 881-892, 2016

19. Bal NC, Maurya SK, Singh S, Wehrens XH and Periasamy M: Increased reliance on muscle-based thermogenesis upon acute minimization of brown adipose tissue function. J Biol Chem 291: $17247-17257,2016$

20. Jonsdottir IH, Schjerling P, Ostrowski K, Asp S, Richter EA and Pedersen BK: Muscle contractions induce interleukin-6 mRNA production in rat skeletal muscles. J Physiol 528: 157-163, 2000.
21. Wallenius V, Wallenius K, Ahrén B, Rudling M, Carlsten H, Dickson SL, Ohlsson C and Jansson JO: Interleukin-6-deficient mice develop mature-onset obesity. Nat Med 8: 75-79, 2002.

22. Rowland LA, Bal NC, Kozak LP and Periasamy M: Uncoupling protein 1 and sarcolipin are required to maintain optimal thermogenesis, and loss of both systems compromises survival of mice under cold stress. J Biol Chem 290: 12282-12289, 2015.

23. Spaeth AM, Kanoski SE, Hayes MR and Grill HJ: TrkB receptor signaling in the nucleus tractus solitarius mediates the food intake-suppressive effects of hindbrain BDNF and leptin. Am J Physiol Endocrinol Metab 302: E1252-E1260, 2012.

24. An JJ, Liao GY, Kinney CE, Sahibzada N and Xu B: Discrete BDNF neurons in the paraventricular hypothalamus control feeding and energy expenditure. Cell Metab 22: 175-188, 2015.

25. Larsen PJ, Tang-Christensen M, Holst JJ and Orskov C: Distribution of glucagon-like peptide-1 and other preproglucagon-derived peptides in the rat hypothalamus and brainstem. Neuroscience 77: 257-270, 1997.

26. Beiroa D, Imbernon M, Gallego R, Senra A, Herranz D, Villarroya F, Serrano M, Fernø J, Salvador J, Escalada J, et al: GLP-1 agonism stimulates brown adipose tissue thermogenesis and browning through hypothalamic AMPK. Diabetes 63: 3346-3358, 2014

27. Lockie SH, Heppner KM, Chaudhary N, Chabenne JR, Morgan DA, Veyrat-Durebex C, Ananthakrishnan G, Rohner-Jeanrenaud F, Drucker DJ, DiMarchi R, et al: Direct control of brown adipose tissue thermogenesis by central nervous system glucagon-like peptide-1 receptor signaling. Diabetes 61: 2753-2762, 2012

28. Kooijman S, Wang Y, Parlevliet ET, Boon MR, Edelschaap D, Snaterse G, Pijl H, Romijn JA and Rensen PC: Central GLP-1 receptor signalling accelerates plasma clearance of triacylglycerol and glucose by activating brown adipose tissue in mice. Diabetologia 58: 2637-2646, 2015.

29. Stefater MA, MacLennan AJ, Lee N, Patterson CM, Haller A, Sorrell J, Myers M, Woods SC and Seeley RJ: The anorectic effect of CNTF does not require action in leptin-responsive neurons. Endocrinology 153: 2647-2654, 2012.

30. Conti B, Sanchez-Alavez M, Winsky-Sommerer R, Morale MC, Lucero J, Brownell S, Fabre V, Huitron-Resendiz S, Henriksen S, Zorrilla EP, et al: Transgenic mice with a reduced core body temperature have an increased life span. Science 314: 825-828, 2006.

31. Coppola A, Liu ZW, Andrews ZB, Paradis E, Roy MC, Friedman JM, Ricquier D, Richard D, Horvath TL, Gao XB, et al: A central thermogenic-like mechanism in feeding regulation: An interplay between arcuate nucleus T3 and UCP2. Cell Metab 5: 21-33, 2007.

32. Schéle E, Benrick A, Grahnemo L, Egecioglu E, Anesten F, Pálsdóttir V and Jansson JO: Inter-relation between interleukin (IL)-1, IL-6 and body fat regulating circuits of the hypothalamic arcuate nucleus. J Neuroendocrinol 25: 580-589, 2013.

33. Shi YC, Lau J, Lin Z, Zhang H, Zhai L, Sperk G, Heilbronn R, Mietzsch M, Weger S, Huang XF, et al: Arcuate NPY controls sympathetic output and BAT function via a relay of tyrosine hydroxylase neurons in the PVN. Cell Metab 17: 236-248, 2013.

34. Bal NC, Singh S, Reis FCG, Maurya SK, Pani S, Rowland LA and Periasamy M: Both brown adipose tissue and skeletal muscle thermogenesis processes are activated during mild to severe cold adaptation in mice. J Biol Chem 292: 16616-16625, 2017.

35. Nedergaard $\mathbf{J}$ and Cannon B: The browning of white adipose tissue: Some burning issues. Cell Metab 20: 396-407, 2014.

36. Jankovic A, Golic I, Markelic M, Stancic A, Otasevic V, Buzadzic B, Korac A and Korac B: Two key temporally distinguishable molecular and cellular components of white adipose tissue browning during cold acclimation. J Physiol 593: 3267-3280, 2015.

37. Li G, Klein RL, Matheny M, King MA, Meyer EM and Scarpace PJ: Induction of uncoupling protein 1 by central interleukin- 6 gene delivery is dependent on sympathetic innervation of brown adipose tissue and underlies one mechanism of body weight reduction in rats. Neuroscience 115: 879-889, 2002. 